OPEN ACCESS

Edited by:

Giuseppe Forlani,

University of Ferrara, Italy

Reviewed by:

Karl Forchhammer,

University of Tübingen, Germany

Vicente Rubio,

Consejo Superior de Investigaciones

Cientificas (CSIC), Spain

Maurizio Chiurazzi,

National Research Council (CNR), Italy

${ }^{*}$ Correspondence:

Francisco M. Cánovas

canovas@uma.es

TORCID:

María Belén Pascual orcid.org/0000-0002-7988-1204

Fernando N. de la Torre orcid.org/0000-0002-5143-3709

Luis Gómez

orcid.org/0000-0003-0667-2302

Concepción Avila

orcid.org/0000-0001-8817-7529

Francisco M. Cánovas

orcid.org/0000-0002-4914-2558

Specialty section

This article was submitted to

Plant Metabolism

and Chemodiversity,

a section of the journal

Frontiers in Plant Science

Received: 20 December 2019

Accepted: 22 May 2020

Published: 16 June 2020

Citation:

Llebrés MT, Pascual MB, Valle $C$ de la Torre FN, Valderrama-Martin JM, Gómez L, Avila C and Cánovas FM

(2020) Structural and Functional

Characteristics of Two Molecular

Variants of the Nitrogen Sensor PII

in Maritime Pine.

Front. Plant Sci. 11:823.

doi: 10.3389/fpls.2020.00823

\section{Structural and Functional} Characteristics of Two Molecular Variants of the Nitrogen Sensor PII in Maritime Pine

\author{
María Teresa Llebrés ${ }^{1}$, María Belén Pascualit, Carolina Valle ${ }^{1}$, Fernando N. de la Torre ${ }^{1 t}$, \\ José Miguel Valderrama-Martin1, Luis Gómez ${ }^{2+}$, Concepción Avila ${ }^{1+}$ and \\ Francisco M. Cánovas ${ }^{1 *+}$ \\ 'Grupo de Biología Molecular y Biotecnología de Plantas, Departamento de Biología Molecular y Bioquímica, Faculty \\ of Science, Universidad de Málaga, Campus Universitario de Teatinos, Málaga, Spain, ${ }^{2}$ Centro de Biotecnología y \\ Genómica de Plantas, Campus de Excelencia Internacional de Montegancedo, Parque Científico y Tecnológico de la \\ Universidad Politécnica de Madrid, Madrid, Spain
}

High levels of nitrogen are stored as arginine during the last stages of seed formation in maritime pine (Pinus pinaster Aiton). The protein sensor PII regulates the feedback inhibition of arginine biosynthesis through interaction with the key enzyme $N$-acetylglutamate kinase (NAGK). In this study, the structural and functional characteristics of PII have been investigated in maritime pine to get insights into the regulation of arginine metabolism. Two different forms of Pll have been identified, PpPlla and PpPllb, which differ in their amino acid sequence and most likely correspond to splicing variants of a single gene in the pine genome. Two Pll variants are also present in other pine species but not in other conifers such as spruces. PpPlla and PpPIlb are trimeric proteins for which structural modeling predicts similar tridimensional protein core structures. Both are located in the chloroplast, where the Pll-target enzyme PpNAGK is also found. PpPIla, PpPIlb, and PpNAGK have been recombinantly produced to investigate the formation of NAGK-PII complexes. The interaction of PpPlla/PpPllb and PpNAGK may be enhanced by glutamine and contribute to relieve the feedback inhibition of PpNAGK by arginine. Expression analysis of PpPll genes revealed that Pplla transcripts were predominant during embryogenesis and germination. The potential roles of PpPlla and PpPllb in the regulation of arginine metabolism of maritime pine are discussed.

Keywords: Pinus pinaster, amino acids, arginine metabolism, isoproteins, nitrogen storage

\section{INTRODUCTION}

Plants, like other organisms, have developed mechanisms to detect and respond to changes in carbon and nitrogen levels. These mechanisms regulate the activity of proteins involved in the transport and metabolism of nitrogen and carbon compounds, allowing plants to optimize their energy sources. These processes are particularly important in trees due to their long life cycles (Cánovas et al., 2018). 
The sensing mechanisms for carbon/nitrogen $(\mathrm{C} / \mathrm{N})$ balance activate genes involved in nitrogen assimilation when carbon skeletons are abundant and internal levels of organic nitrogen are low. On the other hand, they decrease the rate of nitrogen assimilation when the levels of photosynthetic products are low or the internal levels of nitrogen are relatively high. These mechanisms allow plants to adjust their energy and metabolite allocation to a shifting carbon and nitrogen availability (Coruzzi and Zhou, 2001; Gent and Forde, 2017).

The systems to sense and respond to carbon and nitrogen levels have been the subject of elegant studies on microorganisms such as Escherichia coli and yeast (Forchhammer and Lüddecke, 2016). In these unicellular models, signaling systems have been found to be complex and multiple (Jiang et al., 1998). These systems are even more complex in plants, which must respond to various carbon and nitrogen metabolites in different tissues, stages of development, and cell compartments (Ferrario-Méry et al., 2006, 2008). A key protein family of modulators acting in microorganisms and plants is the one of the PII signaling proteins (Selim et al., 2020a). These proteins have as targets channels, enzymes, and transcriptional regulators, influencing the activities of these targets by direct protein-protein interactions with them (Selim et al., 2020a). PII proteins sense the nitrogen, carbon, and energy richness status of the cell via interactions with allosteric effectors [ATP/ADP and 2-oxoglutarate (2OG); and, in plants, also with glutamine] and, in some bacteria, by highly specific postranslational modifications (Forchhammer and Lüddecke, 2016). In this way, PII proteins are signal transductors that play crucial roles for nitrogen/carbon and energy regulation of bacteria and also of plants. They are the main focus of the studies presented here.

PII proteins are homotrimers of a subunit presenting a wellconserved sequence which is folded according to the ferredoxin fold. This fold is made of two $\beta \alpha \beta$ structural repeats, and in PII proteins, it presents three functionally important loops, called T-loop, B-loop, and a C-terminal loop. The T-loop hosts a characteristic invariant sequence motif (Motif I). This loop connects both repeats of the fold, it is long and plastic, and its conformation is influenced by the allosteric effectors of PII, also being in some bacteria the site of covalent modifications at specific residues (as exemplified by the T-loop uridylylation observed in E. coli, Ninfa and Atkinson, 2000). The T-loop plays a key role in the interactions of PII with its protein partners (Selim et al., 2020a). The B-loop also hosts an invariant motif (Motif II) and also participates in the interactions with PII targets (Selim et al., 2020a). The C-terminal loop of plants is called the Q-loop, it is longer than bacterial C-terminal loops, and it is the site of glutamine binding. The adenine nucleotide and 2OG effectors sit at intersubunit crevices at the root of the T-loops.

In bacteria, the signaling PII protein serves as a central processing unit to integrate signals on carbon, nitrogen, and energy abundance status, and use such information to control nitrogen uptake (Ninfa and Atkinson, 2000). The assimilation of ammonium as glutamine is regulated in response to intracellular concentrations of glutamine (a nitrogen signal) and 2-OG (a carbon signal) (Muro-Pastor et al., 2005; Robles-Rengel et al., 2019).
In plants, the PII protein is a sensor of $\mathrm{C} / \mathrm{N}$ status mediated by the binding to 2-OG and glutamine. It subsequently regulates the arginine biosynthetic pathway (Chen et al., 2006; Chellamuthu et al., 2014) which is under feed-back control by arginine inhibition of $\mathrm{N}$-acetylglutamate kinase (NAGK). However, when $\mathrm{N}$ is abundant, the inhibition is relieved through the interaction of NAGK with the sensor protein PII (Chen et al., 2006; Llácer et al., 2007). Increased levels of glutamine are a signal of $\mathrm{N}$ abundance that is sensed via the PII Q-loop and transduced into enhanced activity of NAGK (Chellamuthu et al., 2014). In this way, the connection proposed between PII and arginine-rich protein biosynthesis and deposition in seeds (Urigh et al., 2009) could be regulated by glutamine availability. Other less wellstudied effects of PII on plant nitrogen metabolism include the observation made that in symbiotic nitrogen fixation PII affects the development of root nodules, the mobilization to the host of of the fixed nitrogen, and the signaling of the $\mathrm{N}$ nutritional status (Arcondeguy et al., 2001; D’Apuzzo et al., 2015), as well as the recent report of a potential role of PII in the biosynthetic production of NO (Parlatti et al., 2017).

In trees, when the availability of $\mathrm{N}$ is high, arginine is stored either as a free amino acid or as a component of storage proteins in the bark and seeds (Li and Coleman, 2019). During embryogenesis, nitrogen derived from tissue sources, mainly in the form of glutamine, is transported to developing seeds where it is used for the biosynthesis and deposition of storage proteins. In conifers, arginine is highly abundant in the seed storage proteins and represents an important source of nitrogen for developing plantlets following seed germination (Todd et al., 2001; Todd and Gifford, 2003; Cánovas et al., 2007). Therefore, the regulation of arginine metabolism has a relevant role in the store and mobilization of $\mathrm{N}$ during the embryogenesis and germination of pine (Llebrés et al., 2018a,b).

In vitro somatic embryogenesis in combination with cryopreservation is a major biotechnological tool for vegetative propagation of selected maritime pine varieties for different ecological and economical applications (Trontin et al., 2016). However, a fundamental understanding of how arginine metabolism is regulated during embryogenesis and germination is necessary to improve embryo quality and to generate vigorous maritime pine seedlings via somatic embryogenesis (Llebrés et al., 2018b).

In the present study, key aspects of PII regulation in maritime pine are investigated with the purpose of getting insights into the regulation of arginine biosynthesis in response to nitrogen availability in conifers, a plant group of crucial ecological and economic importance.

\section{MATERIALS AND METHODS}

\section{Plant Material}

Maritime pine embryos were excised from seeds collected from a single seed orchard (Picard, Saint-Laurent-Médoc, France) at different developmental stages (Llebrés et al., 2018b). Pinus pinaster Aiton seeds were provided by the Centro Nacional de Recursos Genéticos Forestales from "Ministerio de Agricultura, 
Pesca, Alimentación y Medio Ambiente," Spain. Seeds were imbibed in distilled water for $24 \mathrm{~h}$ under continuous aeration and germinated and grown with vermiculite as a substrate under a photoperiod of $16 \mathrm{~h}$ light $/ 8 \mathrm{~h}$ dark at $24^{\circ} \mathrm{C}$. Hypocotyls of pine seedlings were collected after 2 weeks, frozen in liquid nitrogen, and stored at $-80^{\circ} \mathrm{C}$ until use. Nicotiana benthamiana L. seeds were sown and grown in pots and maintained under a $16 \mathrm{~h}$ light $/ 8 \mathrm{~h}$ dark photoperiod at $24^{\circ} \mathrm{C}$ for 5 weeks.

\section{Cloning of PpPIla, PpPIlb, and PpNAGK}

The sequences of PpPIIa, PpPIIb, and PpNAGK were retrieved from the maritime pine ( $P$. pinaster) transcriptome available at SustainPineDB v.3.01 . Full-length cDNAs were isolated from pine hypocotyl RNAs by reverse transcription-PCR (RT-PCR) using primers designed from $P$. pinaster sequences (Canales et al., 2014). Extraction of RNA was performed as described by Canales et al. (2012) and quantified using a NanoDrop $\odot$ ND-1000 spectrophotometer. Synthesis of cDNA was performed with $5 \mathrm{X}$ iScript ${ }^{\mathrm{TM}} \mathrm{cDNA}$ Synthesis Kit (Bio-Rad). The primer pairs used for specific amplification are listed in Supplementary Table S1. The resulting PCR products were cloned in a pJet1.2 (Thermo Fisher Scientific ${ }^{\mathrm{TM}}$ ) vector and completely sequenced.

\section{Transient Expression of GFP-Proteins in Nicotiana benthamiana}

PCR amplifications were performed as described above but the stop codons were removed from reverse primer sequences (Supplementary Table S1). The resulting PCR products were cloned into pDONR207 and subcloned into pGWB5 via Gateway technology (Invitrogen) to produce, under the control of the CaMV 35S promoter, full-length proteins fused to GFP at their C-termini (El-Azaz et al., 2016). Empty pGWB5 was used for negative controls. The Agrobacterium tumefaciens strain C58C1 was transformed by electroporation with recombinant plasmids. $N$. benthamiana leaves (5 weeks old) were syringe infiltrated with cultures containing pGWB5 constructs mixed with cultures containing the silencing suppressor p19 protein, both with an optical density of 0.5 at $600 \mathrm{~nm}$, according to previously described procedures (Liu et al., 2002). Subcellular localization of proteins was examined by confocal microscopy $36-48 \mathrm{~h}$ after agroinfiltration.

\section{Transient Expression of GFP-Proteins in Pine Protoplasts}

To perform transient expression assays in pine protoplasts, fusions of PpPIIa with or without its putative chloroplastic transit peptide (cTP) and the GFP reporter gene were constructed using appropriate primers. Protoplasts were prepared from maritime pine cotyledons by incubation of $1 \mathrm{~g}$ of freshly cutted tissue in $10 \mathrm{~mL}$ of a mixture containing $0.44 \%(\mathrm{w} / \mathrm{v}) \mathrm{K} 3$ medium: $0.4 \%$ $(\mathrm{w} / \mathrm{v})$ cellulase, $0.4 \%(\mathrm{w} / \mathrm{v})$ macerase (Calbiochem), and $0.4 \%$ sucrose. Transformation with the gene constructs was performed by electroporation essentially as previously described by GómezMaldonado et al. (2004). After culture in the dark for 18-24 h,

${ }^{1}$ http://www.scbi.uma.es/sustainpinedb/sessions/new the transformed protoplasts were visualized by laser confocal microscopy using a Leica CLSM microscope. Excitation was conducted with a laser beam at $488 \mathrm{~nm}$. Red autofluorescence of chlorophyll was detected up to $560 \mathrm{~nm}$ and green fluorescence of GFP was detected between 505 and $520 \mathrm{~nm}$.

\section{Overexpression and Purification of Recombinant Proteins}

Open reading frames (ORFs) corresponding to PpPIIa and $P$ PIIb without the cTP were PCR-amplified using primers containing appropriate restriction sites. PpPIIa and PpPIIb forward primers contained a NdeI restriction site and the reverse primer contain a XhoI restriction site. Sequences are listed in Supplementary Table S1. PCR products were digested and subcloned into the pET30b at NdeI and XhoI sites. Plasmid constructs were sequenced and subsequently transformed into E. coli strain BL21-AI (Thermo Fisher Scientific). Cells were grown at $37^{\circ} \mathrm{C}$ by shaking in Luria-Bertani broth containing $50 \mu \mathrm{g} \mathrm{mL}^{-1}$ kanamycin until $\mathrm{OD}_{600}=0.6 ; 0.2 \%$ arabinose $(\mathrm{w} / \mathrm{v})$ was added, and cultures were further incubated for $5 \mathrm{~h}$ at $30^{\circ} \mathrm{C}$ with shaking. Cells were pelleted by centrifugation at 4,500 $\times g$ and frozen. ORF corresponding to PpNAGK without the cTP was amplified using a specific forward primer (Supplementary Table S1). The resulting PCR product was cloned into the pDONR207, subcloned into the pDest17 vector via Gateway Technology (Invitrogen), and transformed into E. coli strain BL21-AI (Thermo Fisher Scientific). Bacterial growth and protein induction requirements were the same as described above but the media contained $100 \mu \mathrm{g} \mathrm{mL} \mathrm{m}^{-1}$ ampicillin instead. Recombinant proteins were purified by binding onto Ni-agarose resin (Protino NiNTA; Macherey-Nagel). Protein concentrations were determined by the Bradford dye-binding method (Bradford, 1976) and analyzed by SDS-PAGE to verify purification.

\section{PpNAGK Activity Assays}

The activity assay based on $N$-acetylglutamylhydroxamate production was performed according to the method described by Heinrich et al. (2004). The reaction mixture consisted of $400 \mathrm{mM} \mathrm{NH}{ }_{2} \mathrm{OH}-\mathrm{HCl}, \mathrm{pH} \mathrm{7,} 20 \mathrm{mM}$ Tris/Cl, pH 7, $20 \mathrm{mM}$ $\mathrm{MgCl}_{2}, 40 \mathrm{mM}$ NAG, and $10 \mathrm{mM}$ ATP. Reactions were initiated by the addition of reaction mixture, the incubation was carried out at $37^{\circ} \mathrm{C}$ in a volume of $150 \mu \mathrm{L}$ and terminated by the addition of $150 \mu \mathrm{L}$ of stop mixture [1:1:1 of $5 \%(\mathrm{w} / \mathrm{v}) \mathrm{FeCl}_{3} \cdot 6 \mathrm{H}_{2} \mathrm{O}$ in $0.2 \mathrm{M} \mathrm{HCl}, 8 \%(\mathrm{w} / \mathrm{v})$ trichloroacetic acid, and $0.3 \mathrm{M} \mathrm{HCl}$. After standing for $5 \mathrm{~min}$ at room temperature, the tubes were centrifuged and the absorbance was immediately measured at $540 \mathrm{~nm}$. The absorbance change was linear with time of incubation in the enzyme assay for at least $30 \mathrm{~min}$. Controls were carried out that did not contain $N$-acetylglutamate. There was no activity when no NAGK was added. To estimate the molar amount of $N$-acetylglutamylhydroxamate formed a molar absorption coefficient was used of $456 \mathrm{M}^{-1} \mathrm{~cm}^{-1}$ at $540 \mathrm{~nm}$ (Heinrich et al., 2004).

$\mathrm{N}$-acetylglutamate kinase activity was also determined by a continuous spectrophotometric assay in which the production of ADP was coupled to $\mathrm{NADH}$ oxidation via pyruvate kinase 
(PK) and lactate dehydrogenase (LDH) (Cánovas et al., 1984). The reaction mixture containing $100 \mathrm{mM}$ Hepes, pH7, $10 \mathrm{mM}$ $\mathrm{MgCl}_{2}, 10 \mathrm{mM}$ ATP, $40 \mathrm{mM} N$-acetylglutamate, $1 \mathrm{mM}$ phosphoenolpyruvate, $0.6 \mathrm{mM} \mathrm{NADH}$, and 1 unit each of PK and $\mathrm{LDH}$. Assays were performed in $100 \mu \mathrm{L}$ volumes and incubated at $37^{\circ} \mathrm{C}$ in multi-well plates for $5 \mathrm{~min}$. The blank reactions did not contain $\mathrm{N}$-acetylglutamate.

\section{Gel Filtration Chromatography of Purified PII Proteins}

Protein samples were diluted to a concentration of $0.6 \mu \mathrm{g} / \mu \mathrm{L}$ in a solution of $25 \mathrm{mM}$ Tris- $\mathrm{HCl}, \mathrm{pH} 7.5,150 \mathrm{mM} \mathrm{NaCl}, 10 \%$ (v/v) glicerol, and a $250 \mu \mathrm{L}$ sample was then chromatographed on a ENrich ${ }^{\text {TM }}$ SEC $65010 \times 300$ column (BioRad) equilibrated at room temperature in Tris/ $\mathrm{HCl}$ buffer. The fast protein liquid chromatography flow rate was $0.75 \mathrm{~mL} / \mathrm{min}$, and $100 \mu \mathrm{L}$ fractions were collected.

The column was calibrated with ribonuclease A $(13.7 \mathrm{kDa})$, carbonic anhydrase $(29 \mathrm{kDa})$, bovine serum albumin (66 kDa), alcohol dehydrogenase $(150 \mathrm{kDa})$, ß-amylase $(200 \mathrm{kDa})$, apoferritin $(440 \mathrm{kDa})$, and blue dextran (void volume of the column).

\section{Western Blot and Antibody Production}

The presence of proteins in the elution fractions was detected by SDS-PAGE and western blot analysis with anti-PII antibodies as described previously (Cánovas et al., 1991). Antibodies against PpPIIa were raised in rabbits by immunization with PpPIIa recombinant protein overexpressed in $E$. coli as described by Cantón et al. (1996). The primary antibodies anti-PpPIIa were used at 1:10,000 dilution and a 1:10,000 dilution of horseradish peroxidase conjugated antirabbit serum (Sigma) was used as a secondary antibody.

\section{Yeast Two-Hybrid Assay}

Interaction assays in yeast were performed with the yeast TwoHybrid System (YTH) of Invitrogen. PpNAGK was cloned into Gateway pDEST22 vector by LR recombination reaction to form the prey plasmid, whereas PpPIIa and PpPIIb were cloned into Gateway pDEST32 vector by LR recombination reaction to form the bait plasmids. Two mutations were produced in PpPIIa corresponding to a single change of a glutamate for lysine (Glu18Lys) and a triple amino acid change: valine, alanine, and glycine, for alanine, glycine, and alanine (Val58Ala/Ala60Gly/Gly61Ala). Site-directed mutagenesis was performed through a PCR-based strategy using iProof highfidelity DNA polymerase (Bio-Rad) and cloned into pDEST32 vector. Specific primers were used for amplification under the following conditions: $2 \mathrm{~min}$ at $98^{\circ} \mathrm{C}$, followed by 20 cycles $\left(10 \mathrm{~s}\right.$ at $98^{\circ} \mathrm{C}, 20 \mathrm{~s}$ at $60^{\circ} \mathrm{C}$, and $7 \mathrm{~min}$ at $72^{\circ} \mathrm{C}$ ) and a final elongation of $4 \mathrm{~min}$ at $72^{\circ} \mathrm{C}$. Samples were treated with $D p n \mathrm{I}$ (Thermo Scientific ${ }^{\mathrm{TM}}$ ) to eliminate native methylated plasmid DNA, and the PCR product was transformed into E. coli DH5 $\alpha$ with selection on $100 \mu \mathrm{g} \mathrm{mL}^{-1}$ gentamicin. All of the constructs were verified by sequencing and co-transformed into yeast stain MAV203 using the LiAc method following the yeast transformation instructions of Invitrogen. Transformed yeasts were selected at $30^{\circ} \mathrm{C}$ on synthetic defined (SD) media agar plates without leucine and tryptophan.

To identify strong interactions, individual transformants were characterized on SD agar plates without leucine, tryptophan, and histidine, supplemented with 10, 25, 50, and $100 \mathrm{mM}$ 3-AT (3Amino-1, 2, 4-triazole, Sigma) and on SD agar plates without leucine, tryptophan, and uracil.

Positive colonies were grown in liquid media to the stationary phase. Aliquots of $1 \mathrm{~mL}$ were taken and cells were pelleted at $11,000 \times g$ for $30 \mathrm{~s}$, the media was removed and the cells were then washed five times with sterile distilled water (SDW). Cells were then resuspended in SDW and diluted 10, 100 , and 1000 times. A volume of $10 \mu \mathrm{L}$ from each sample was spotted onto plates containing SD media without leucine, tryptophan, and uracil. Plates were incubated at $30^{\circ} \mathrm{C}$ for 3 days and photographed.

\section{Quantitative $\beta$-Galactosidase Assay}

Strong YTH interactions of PpNAGK with PpPIIa and PpPIIb were quantified by the liquid $\beta$-galactosidase assay with ONPG (o-nitrophenyl $\beta$-D-galactopyranoside; Sigma Cat No. N-1127), following the Yeast Protocols Handbook user manual from Clontech Laboratories. All measurements were made in triplicate.

\section{RNA Extraction and Expression Analysis}

RNA extraction from maritime pine samples was performed as described by Canales et al. (2012). Synthesis of cDNA was made with $5 \mathrm{X}$ iScript ${ }^{\mathrm{TM}}$ cDNA Synthesis Kit (Bio-Rad). The qPCR analysis was done in a thermal cycler CFX384 (BioRad). Sequences of PpPIIa and PpPIIb specific primers are listed in Supplementary Table S1. Actin-7 was used as a reference gene. Relative expression profiles for each gene were obtained employing the R package (Ritz and Spiess, 2008) and normalized to the reference gene. For the qPCR analysis, three biological replicates and three technical replicates per sample were made.

\section{Structural Modeling and Calculations}

Structural models for PpPIIa and PpPIIb were generated with the Swiss-Model Server (Biasini et al., 2014) using as template the structure of the Chlamydomonas PII protein as observed in its crystal structure in complex with the NAGK from Arabidopsis thaliana (PDB entry 4USJ, chain C). Alternative models were generated with the I-TASSER suite (Yang et al., 2015), from which the geometry of the first 10 residues was predicted. Energy minimization and structural superpositions were performed with the 1.11.2 version of the UCSF Chimera package ${ }^{2}$ (Pettersen et al., 2004). The electrostatic Poisson-Boltzmann (PB) potential was deduced with the 300 APBS tools in PyMol 1.7.6.7 (Schrödinger, LLC) assigning AMBER atomic charges and radii. The non-linear $\mathrm{PB}$ equation was solved in sequential multigrid calculations at $298 \mathrm{~K}$ with dielectric constants of 2 for proteins and 78.54 for water. Values of potential are given in $\mathrm{kT}$ units per unit charge ( $\mathrm{k}$, Boltzmann's constant; T, absolute temperature). PB potentials

\footnotetext{
${ }^{2}$ www.rbvi.ucsf.edu/chimera
} 
mapped onto protein surfaces were rendered with PyMOL. Other figures were rendered with UCSF Chimera.

\section{RESULTS}

\section{In silico Profile of Maritime Pine PII}

Recent developments in next generation sequencing have provided a range of genomic resources for maritime pine (Canales et al., 2014; Cañas et al., 2017, 2019). The in silico analysis of its transcriptome revealed the existence of two different transcripts encoding putative PII proteins that were named PpPIIa and PpPIIb (Supplementary Figure S1). A striking characteristic of these transcripts is that their sequences mostly differ in the 5'-unstranslated region and the ORF, with minor changes in the 3'-unstranslated region (Supplementary Figure S1).

The ORFs of PpPIIa and PpPIIb encode polypeptides of similar size, with PpPIIa being three amino acids longer (Supplementary Table S2). Upon removal of the putative cTP, mature PpIIa and PpIIb proteins would have equal number of amino acids although their sequences differ in 15 amino acid residues ( $\sim 90 \%$ identity), with all the amino acid changes spread over the first half of the amino acid sequence of the mature putative proteins (Figure 1). Whereas most changes are conservative, a substantial change of glutamate for lysine was identified at position 18 of the mature proteins (Figure 1A, asterisk). Since only a single form of PII has been previously described in angiosperms, the occurrence of PII variants was further investigated in those conifers for which transcriptomic data are available. In addition to $P$. pinaster, several pine species contain two PII variants, including Pinus taeda, Pinus contorta, and Pinus lambertiana. However, only one PII form was found in spruce species (Figure 1B). Their amino acid sequences were highly conserved in pine including the aforementioned nonconservative shift at position 18 . The phylogenetic analysis of PII protein variants clearly classified the pine proteins in two separate clusters, with the PIIb cluster being closer to PII proteins from other conifer species that represent an intermediate branch between pines and herbaceous plants (Figure 1C).

\section{Localization of Maritime Pine PpPII}

To further understand the biological roles of these proteins, their subcellular localization was determined (Figure 2). The ORFs of PpPIIa and PpPIIb were PCR-amplified and cloned into the Gateway vector pGWB5 and the resulting GFP fusions were transiently expressed in $N$. benthamiana leaves via agroinfiltration. The GFP fluorescence of both PpPIIa and PpPIIb fusion products was exclusively associated to chloroplasts, which were visualized by the red autofluorescence of chlorophyll. The merged images showed co-localization of chlorophyll (red) with both GFP-PpPIIa and GFP-PpPIIb (yellow) in the chloroplasts, indicating a plastidic localization for both proteins (Figures 2A1,A2).

To further substantiate this finding, GFP fusions for PpPIIa were constructed with and without cTP and electroporated into isolated maritime pine protoplasts. Figure 2B shows that
GFP-PpPIIa constructs containing the cTP were appropriately targeted to the chloroplasts (Figure 2B2), as it was also observed for control constructs with cTP but lacking the PpPIIa coding sequence (Figure 2B4). However, only cytosolic GFP signals were observed for the constructs lacking cTP (Figure 2B3).

\section{Structural Models of PpPIla and PpPIlb}

To gain insight into the functional significance of the amino acid differences found between mature PpPIIa and PpPIIb, their three-dimensional structures were modeled with the SwissModel server using as template the reported structure of Chlamydomonas PII (taken from PDB entry 4USJ, see section "Materials and Methods"), as well as by using I-TASSER, which chooses automatically model structures from the PDB database. Despite the different approaches and models used by these servers, both servers predicted essentially the same geometries for the protein cores (RMSD of 0.63-0.64 $\AA$ ). The overall fold (137 residues) was remarkably similar to the X-ray structures of PII proteins previously crystallized in complex with NAGK, such as A. thaliana PII (AtPII; PDB entry 2RD5; Mizuno et al., 2007), Synechococcus elongatus PII (SePII; PDB entry 2V5H; Llácer et al., 2007), and Chlamydomonas reinhardtii (CrPII; PDB entry 4USJ; Chellamuthu et al., 2014) (Figure 3A). CrPII was the template we selected for Swiss-Model, to obtain atomic coordinates for the Q-loop residues (see below). The structural alignment of these experimentally solved proteins with PpPIIa rendered RMSD values as low as $0.29 \AA$ (CrPII; 132 C $\alpha$ pairs), $0.67 \AA$ (AtPII; $127 \mathrm{C} \alpha$ pairs), and $0.70 \AA$ (105 C $\alpha$ pairs), bolstering the validity of the predicted geometries. PpPIIa and PpPIIb appeared to contain all the secondary structure elements distinctive of PII proteins (reviewed by Forchhammer and Lüddecke, 2016), including the T-loop involved in $\mathrm{Mg}^{2+}$. ATP binding and the C-terminal Q-loop for glutamine sensing (Figure 3B). PII proteins from cyanobacteria and Brassicaceae lack a glutamine binding site at the C-terminal part of the polypeptide (SePII and AtPII in Figure 3A). The conserved spatial positions of key residues for ligand binding allowed us to dock $\mathrm{Mg}^{2+}$. ATP in the T-loop of both models, and the same is true for glutamine in the Q-loop (Figure 3B). Based on the known architectures for PII-NAGK complexes, we also analyzed the putative contact region with NAGK. Specific residues of the pine PIIs can be predicted to stabilize the heterodimer by interacting with complementary groups located near the end of helices $\alpha \mathrm{E}$ and $\alpha \mathrm{G}$ of NAGK as well as in the neighboring strands $\beta 6$ and $\beta 7$ (Figure 3C). On the PII side, the key interacting residues were located at the end of the a1-helix (W31) and in the T-loop (mainly R65, S69, and E70; numbering for PpPIIa). More specifically, W31 would participate in both hydrogen bonding (backbone) and hydrophobic contacts, whereas the T-loop residues are predicted to form hydrogen bonds and electrostatic interactions with oppositely charged residues of NAGK. While the above structural analyses are consistent with a common mechanism of action for PpPIIa and PpPIIb, calculations of the $\mathrm{PB}$ electrostatic potential might explain the presence of two isoforms in maritime pine. We performed a thorough comparison of the electrostatic potential projected onto the surface of both proteins and did not find 


\section{A}

P.pinaster_PIIa 1 MAAHLPLFVKGSIFSLPSSTSTSSSCTYSSISHTAASPGFHSSPAAANKSVKLGTMORMDGVRSVKHRMTSLHAKMEKRQQIK P.pinaster_PIIb 1 MPAHTLLFANGSLLSLSSS---SSSFTCSSTCNAAACAGFHSSPAAVNNSVKWGAVHRMNGVRWVNHRIVILDGKMKKOQQIK $\rightarrow$

P.pinaster_PIIa 84 ASAQAPNGTNTHPDYVPEANFYKVEAILRPWRISHVTTGLLKMGIRGVTVSDVRGFGVQAGSAERQAGSEFSKDNFVSKIKME P.pinaster_PIIb 81 ASAQAPNATNTCPDYIPKANFYKVEAILRPWRMSHVNSGLLKLGVHGVTVSDVKGFGAQGASAERQAGSEFSKDNFVSKVKME

\begin{tabular}{cc} 
Motif I \\
\hline Pinaster PIIa 167 IVVSKDOVEAVIDAIIDEARTGEIGDGKIFVVPVADVIRVRTGERGLEAERMAGGRSEILTGVHOEVTDSN
\end{tabular} $\begin{array}{lll}\text { P.Pinaster_PIIa } & 167 \text { IVVSKDQVEAVIDAIIDEARTGEIGDGKIFVVPVADVIRVRTGERGLEAERMAGGRSEILTGVHQEVTDSN } \\ \text { P.Pinaster_PIIb } & 164 \text { IVVSKDQVEAVIDAIIDEARTGEIGDGKIFVVPVADVIRVRTGERGLEAERMAGGRSEILTGVHQEVTDSN }\end{array}$ Motif II

B

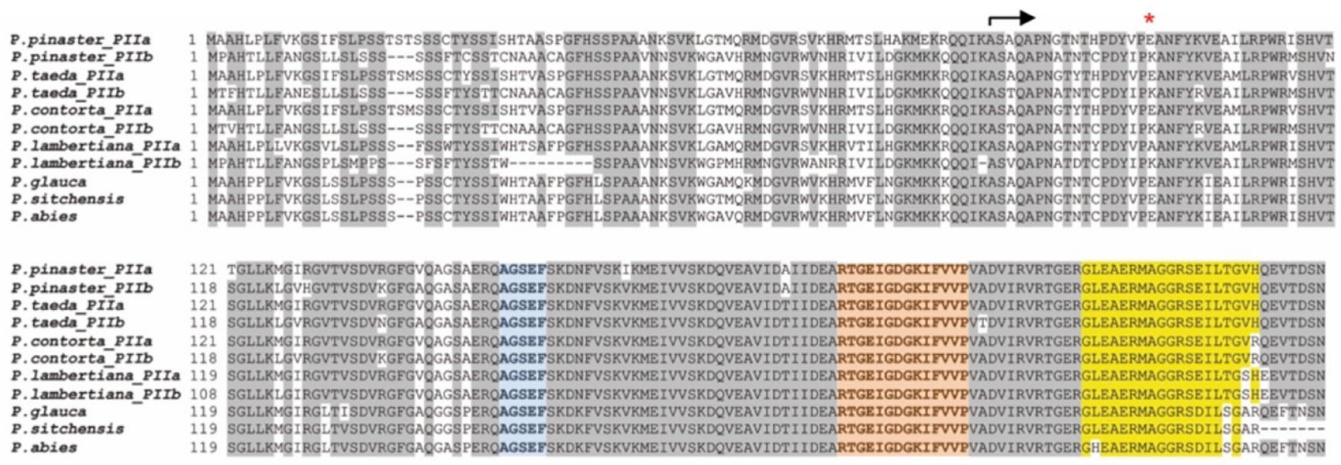

C

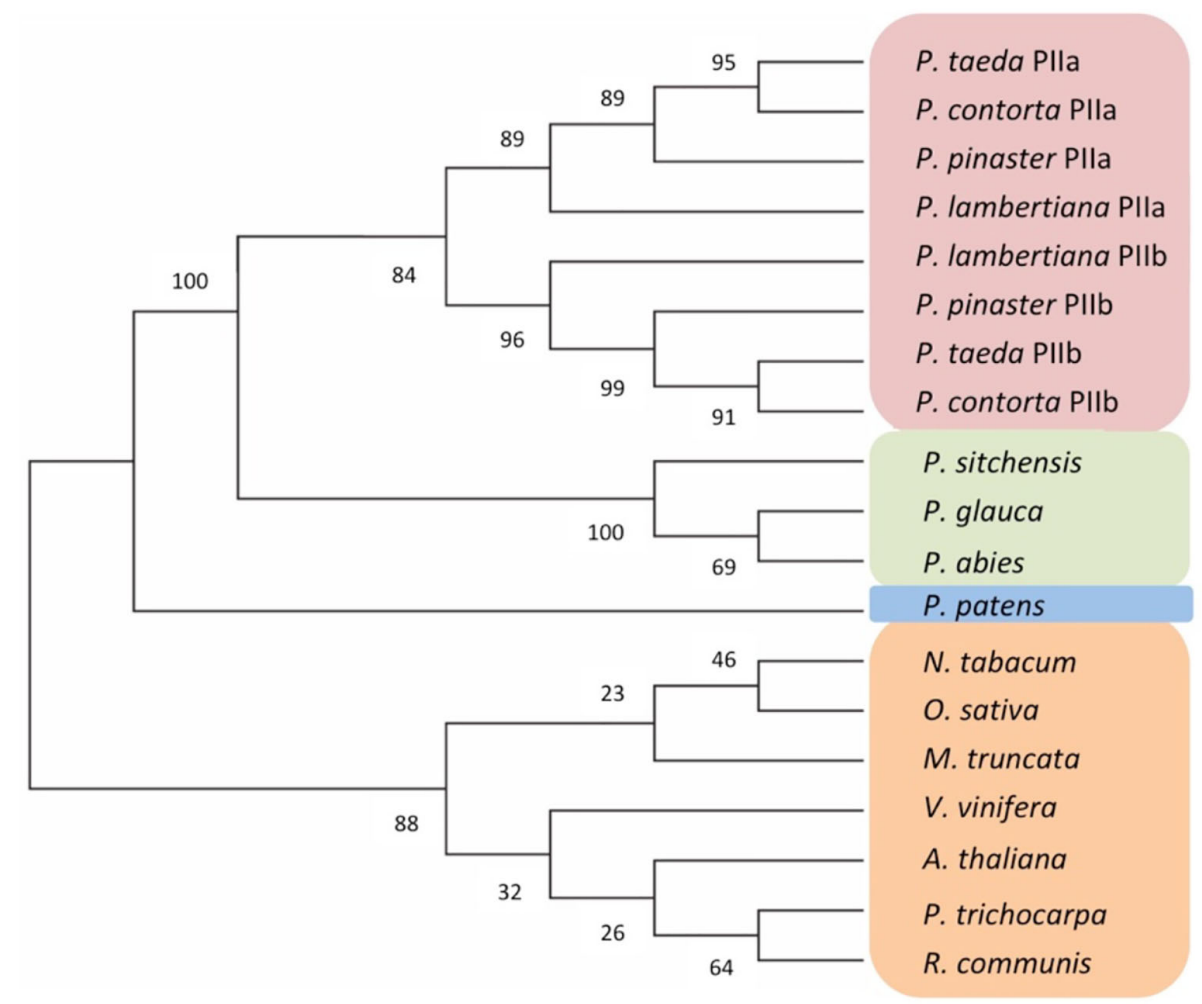

FIGURE 1 | Comparison of PII sequences. (A) Predicted PpPII protein sequences. The conserved sequence motifs (I and II) and the Q Loop position are boxed. The beginning of both mature polypeptides is indicated by an arrow. Residues differing in the two variants are marked in red. The red asterisk highlights a significant amino acid change at position 18 of the mature proteins (see text). (B) Multiple alignments of PII proteins from pine species executed with Clustal X. Conserved sequence motifs in PII proteins are highlighted: in blue Motif I, in orange Motif II, and in yellow the conserved Q-loop of plants. (C) Phylogenetic analysis of PII proteins in angiosperm and gymnosperm species. Alignments were imported into the Molecular Evolutionary Genetics Analyses (MEGA) software version 7.0 (Kumar et al., 2016). The phylogenetic tree was constructed with the full-length Pll amino acid sequences using the neighbor-joining method. Protein sequences were obtained from the following databases: NCBI (www.ncbi.nlm.nih.gov), PlantGDB (www.plantgdb.org), TAIR (https://www.arabidopsis.org), SustainPineDB v.3.0 (http://www.scbi.uma.es/sustainpinedb/sessions/new), and PLAZA (https://bioinformatics.psb.ugent.be/plaza/versions/gymno-plaza). 


\section{PpPlla}

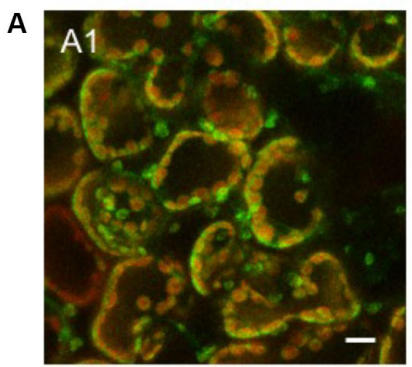

B
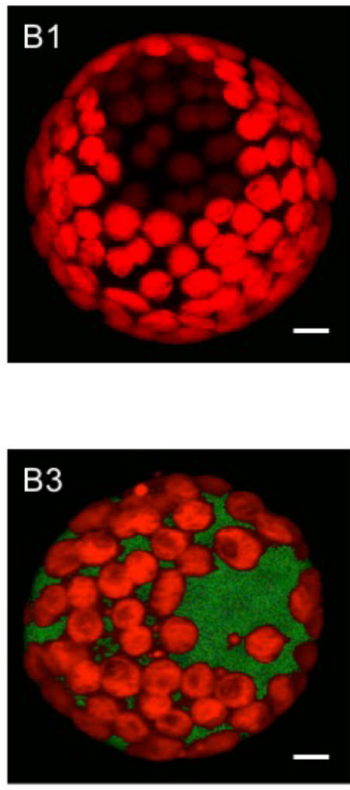

\section{PpPIlb}
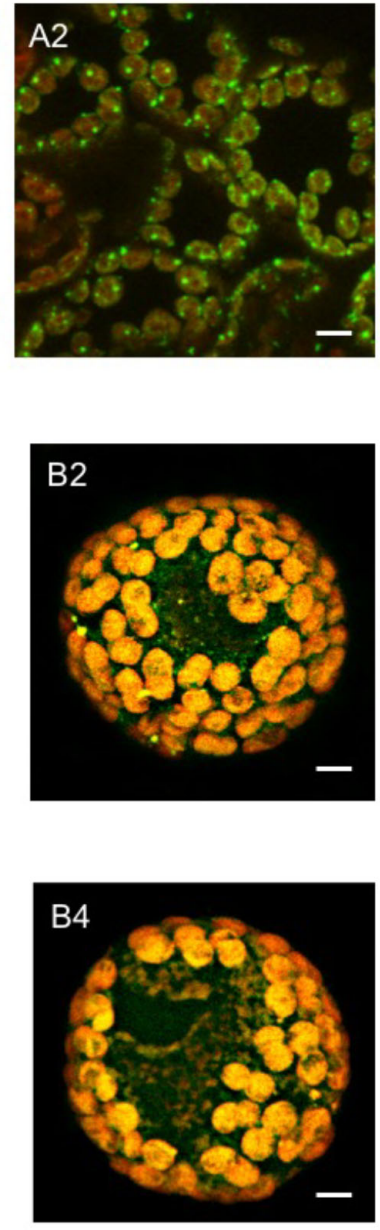

FIGURE 2 | Subcellular localization of PpPIla and PpPllb. (A) Localization in $N$. benthamiana leaves. (A1,A2) GFP-chlorophyll merged images showing respective localizations in the chloroplast of PpPlla and PpPllb.

(B) Localization in isolated pine protoplasts. A single cell is shown containing plastids. (B1) control with no construct; (B2) GFP-PpPlla construct containing transit peptide (cTP); (B3) GFP-PpPlla construct without cTP; (B4) GFP-control construct without the PpPlla protein but containing CTP. Scale bar represents $10 \mu \mathrm{m}$.

any significant difference for the regions involved in interacting with NAGK (Figure 3D, left) or PII trimerization (not shown). However, a significant effect was observed for the substitution of glutamate at position 18 of PpPIIa for lysine in PpPIIb. This notable change in the electrostatic features of the $\mathrm{N}$-terminal extension (Mizuno et al., 2007) occurs in the vicinity of the Q-loop, not far from the glutamine-binding pocket (Figure 3D right). It has been suggested that such $\mathrm{N}$-terminal extension, which maps on the opposite side of the trimer than the surface of interaction with NAGK, may be involved in protein-protein interactions and signaling (Mizuno et al., 2007; Selim et al., 2020a). Interestingly, most non-conservative mutations occur in this extension (see the alignments presented in Figure 1).

\section{Activity of the Complex PpNAGK-PpPII}

The mature PII isoproteins from maritime pine were recombinantly expressed in $E$. coli to raise monospecific antibodies and for further characterization (Supplementary Figure S2). Moreover, sufficient amounts of recombinant native proteins were necessary to perform functional studies on the interaction of PpPIIa and PpPIIb with pine NAGK (PpNAGK) and to investigate how this interaction is regulated by the availability of glutamine and 2-OG.

The native molecular mass of PpPIIa and PpPIIb was determined by gel filtration chromatography through a FPLC column calibrated with protein standards (Figure 4). The molecular mass of both holoproteins was estimated to be $57 \mathrm{kDa}$, a figure compatible with a trimeric structure for the native proteins.

The target enzyme of maritime pine PpPII proteins is PpNAGK, a protein of 352 amino acids. The N-terminus of the predicted polypeptide targets the protein to plastids, where the mature enzyme has been recently localized (Llebrés et al., 2018b). To examine the potential differences in the interaction of PpPIIa and PpPIIb with their target enzyme, a full-length cDNA for PpNAGK was amplified using appropriate primers. A construct encoding the mature PpNAGK enzyme (301 residues without cTP) was fused to a His-tag and overexpressed in E. coli. The resulting recombinant protein was purified by affinity chromatography and next used for additional studies.

The enzyme activity of PpNAGK was increased up to aproximately fivefold when any of the two PII proteins was added in increasing concentrations (Figure 5A). Higher concentrations of PpIIa than of PpPIIb protein appeared necessary to achieved full activation of NAGK, with the maximal activation being similar for the two isoproteins. Potential differences in the interaction of PpPII isoproteins and PpNAGK were further examined by YTH analysis (Supplementary Figure S3). As depicted in Supplementary Figure S3A, the interaction was much weaker for PpPIIb-PpNAGK than for PpPIIa-PpNAGK. To study the molecular basis of this difference, we performed mutations in the PpPIIa sequence, including the change of glutamate for lysine at position 18 (Glu18Lys) and the switch of the three amino acids near the T-loop (valine, alanine, and glycine for alanine, glycine, and alanine) at positions 58, 60, and 61, respectively (Val58Ala/Ala60Gly/Gly61Ala) (Supplementary Figure S3B). Quantitative comparisons using the $\beta$-galactosidase assay confirmed the observed differences in the formation of PpPII-PpNAGK complexes and showed that these amino acid changes did not affect the interaction of PpPIIa with PpNAGK.

To further characterize the sensor properties of PpPIIa and PpPIIb toward PpNAGK, the effect of glutamine was studied in the presence of varying amounts of arginine. When the PpPIIaPpNAGK complex was allowed to form, arginine inhibition was significantly relieved by adding glutamine (Figure 5B). Interestingly, a similar effect of glutamine was observed for the PpPIIb-PpNAGK complex (Figure 5C).

Subsequent experiments were undertaken to study whether PpNAGK activity could be affected by the interaction of both PpPIIa and PpPIIb at varying levels of 2-OG. As shown in Supplementary Figure S4, the addition of PpPIIa and 
A

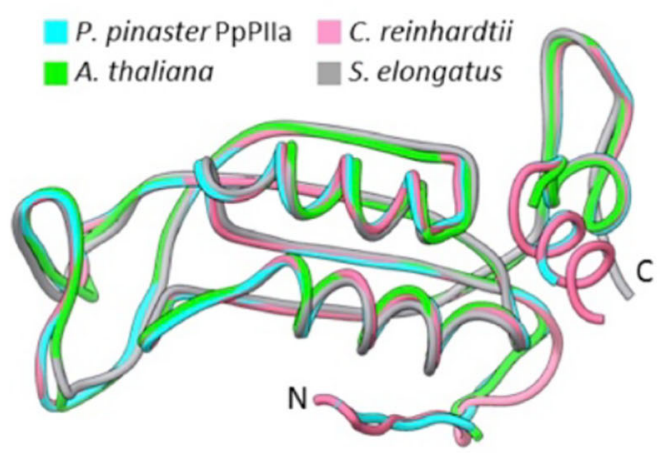

B

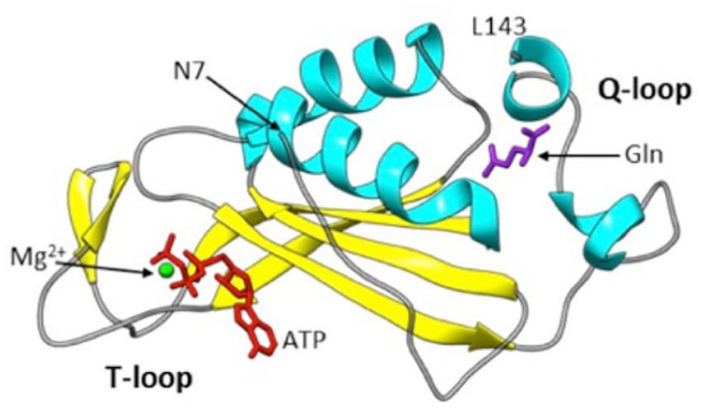

C

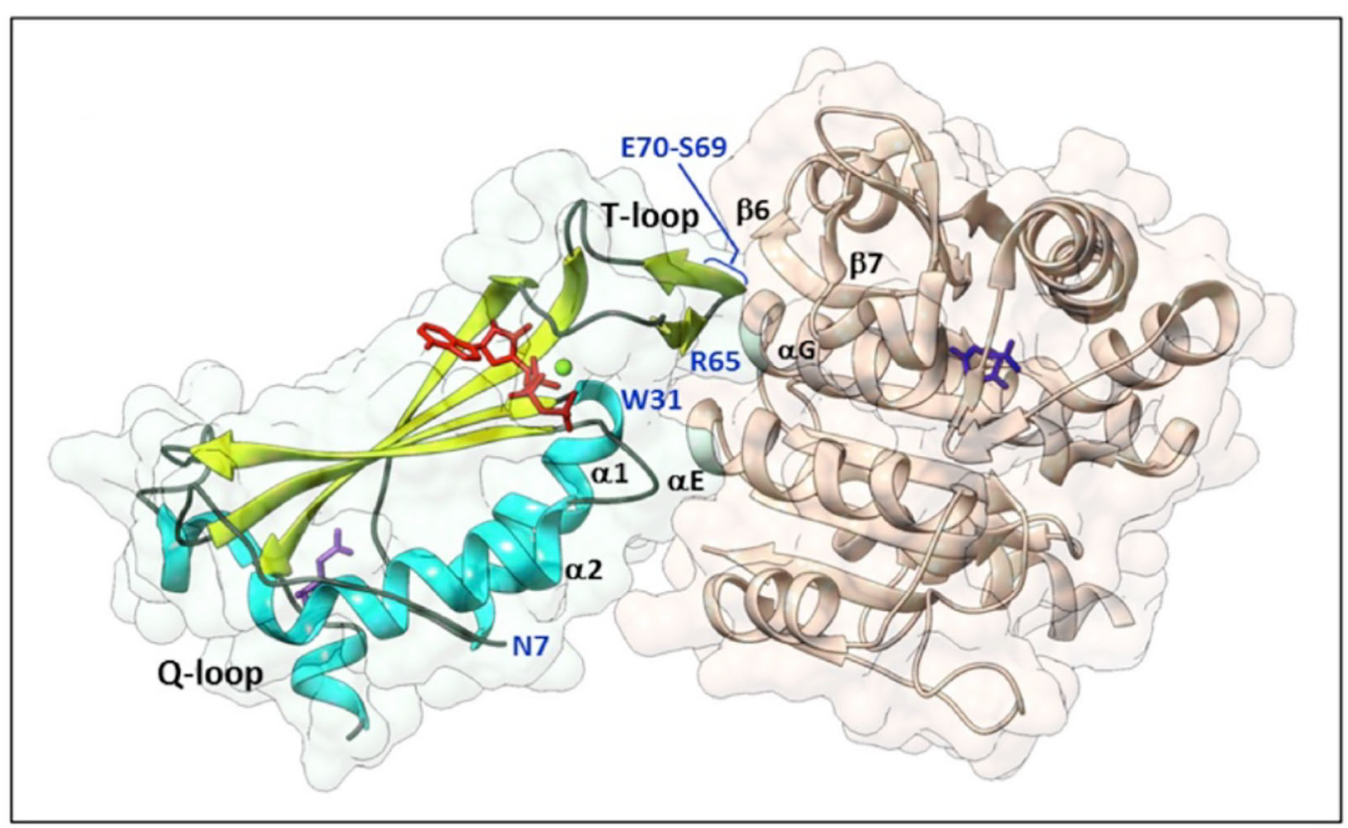

D

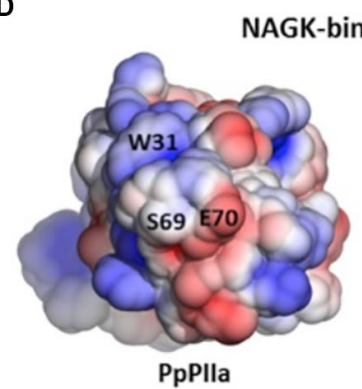

NAGK-binding region
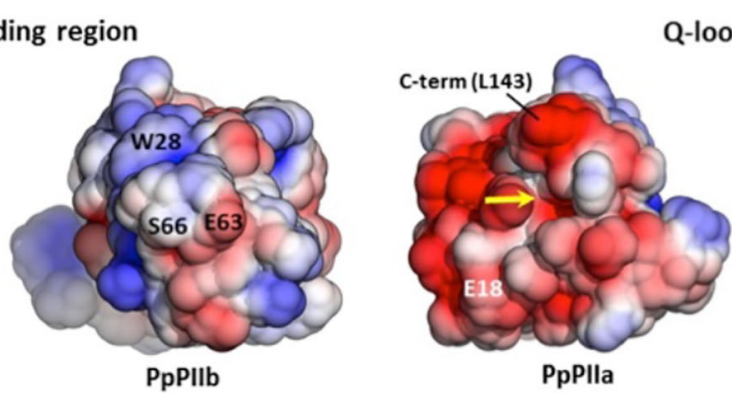

Q-loop region

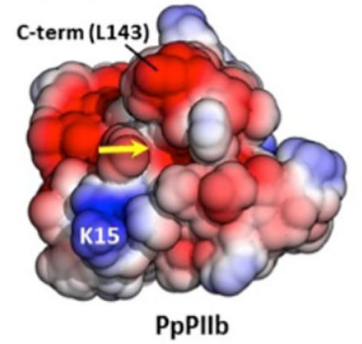

FIGURE 3 | Model structures for PpPIla and PpPIllb. (A) Structural alignment of modeled PpPlla and the experimentally solved structures for AtPII (PDB entry 2RD5), SePII (PDB entry 2V5H), and CrPII (PDB entry 4USJ), three homologous proteins crystallized in complex with NAGK and various ligands. (B) Cartoon representation of PpPlla, highlighting the position of the N-terminal extension, the T-loop and the Q-loop. The position of L143 (PpPlla numbering; C-terminal end of the model) is also indicated. Docked ligands: $\mathrm{Mg}^{2+}$ (green), ATP (red), and glutamine (purple). Compared to (A), this view is rotated about $90^{\circ}$ upward. (C) Side view of a dimer between PpPlla and/**/NAGK from A. thaliana (PDB code 2RD5). The Pll residues directly involved in interactions with the Arabidopsis enzyme are highlighted in blue, like the $\mathrm{N}$-terminus of the model (N7). A molecule of $\mathrm{N}$-acetylglutamate is shown at the active site of AtNAGK (dark blue). (D) Electrostatic potential distribution mapped to the solvent-accessible surfaces of Plla and Pllb at two opposed ends: the region for NAGK binding (left pair) and the confluence of the N-terminal extension and the Q-loop (right pair). The glutamine-binding site is indicated by a yellow arrow. The potential is shown as a colored gradient from red (acidic) at - 2.5 $\mathrm{kT} / \mathrm{e}$ to blue (basic) at $2.5 \mathrm{kT} / \mathrm{e}$ (where $\mathrm{k}$ is Boltzmann's constant, T is temperature, and e is the charge on an electron). 


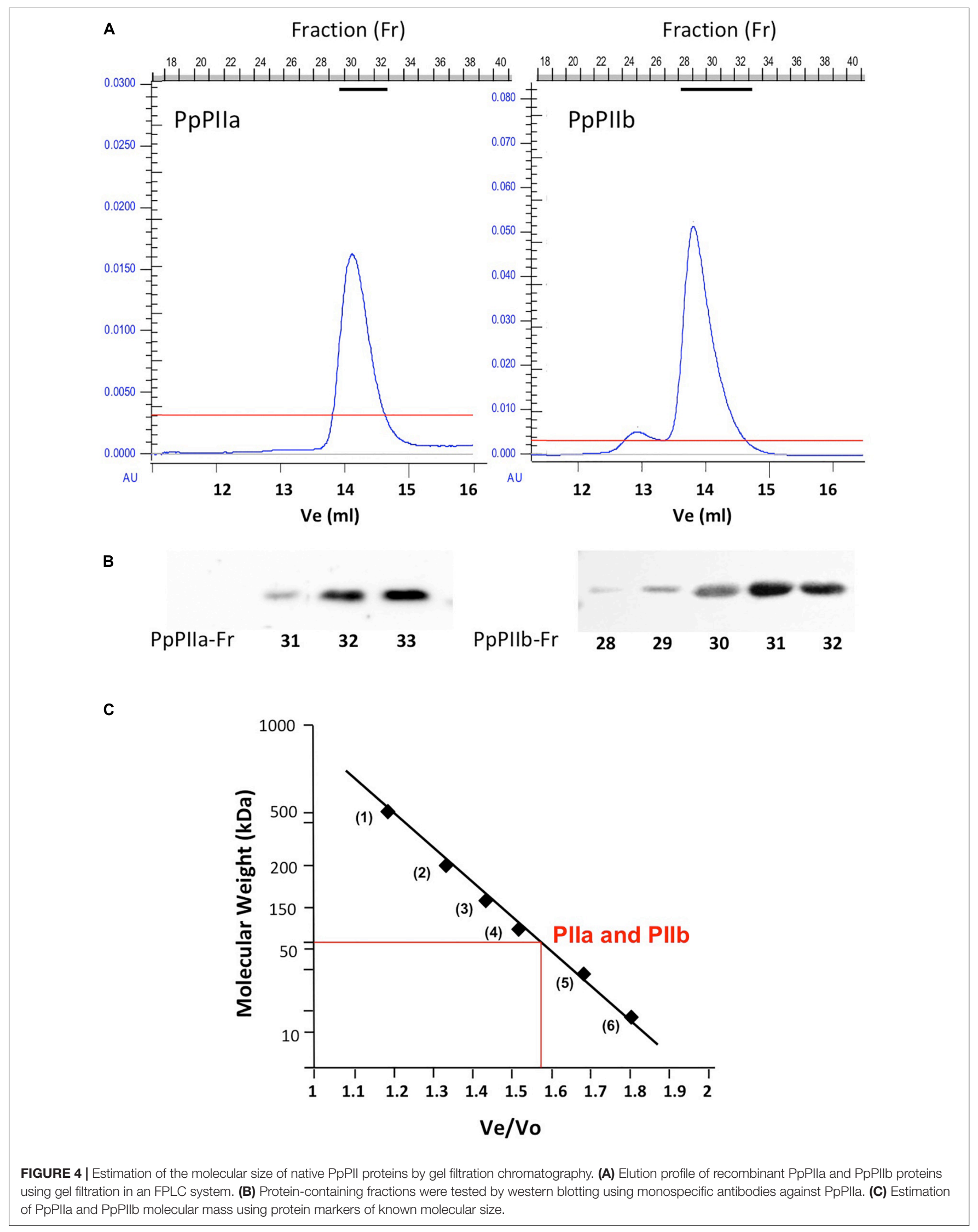



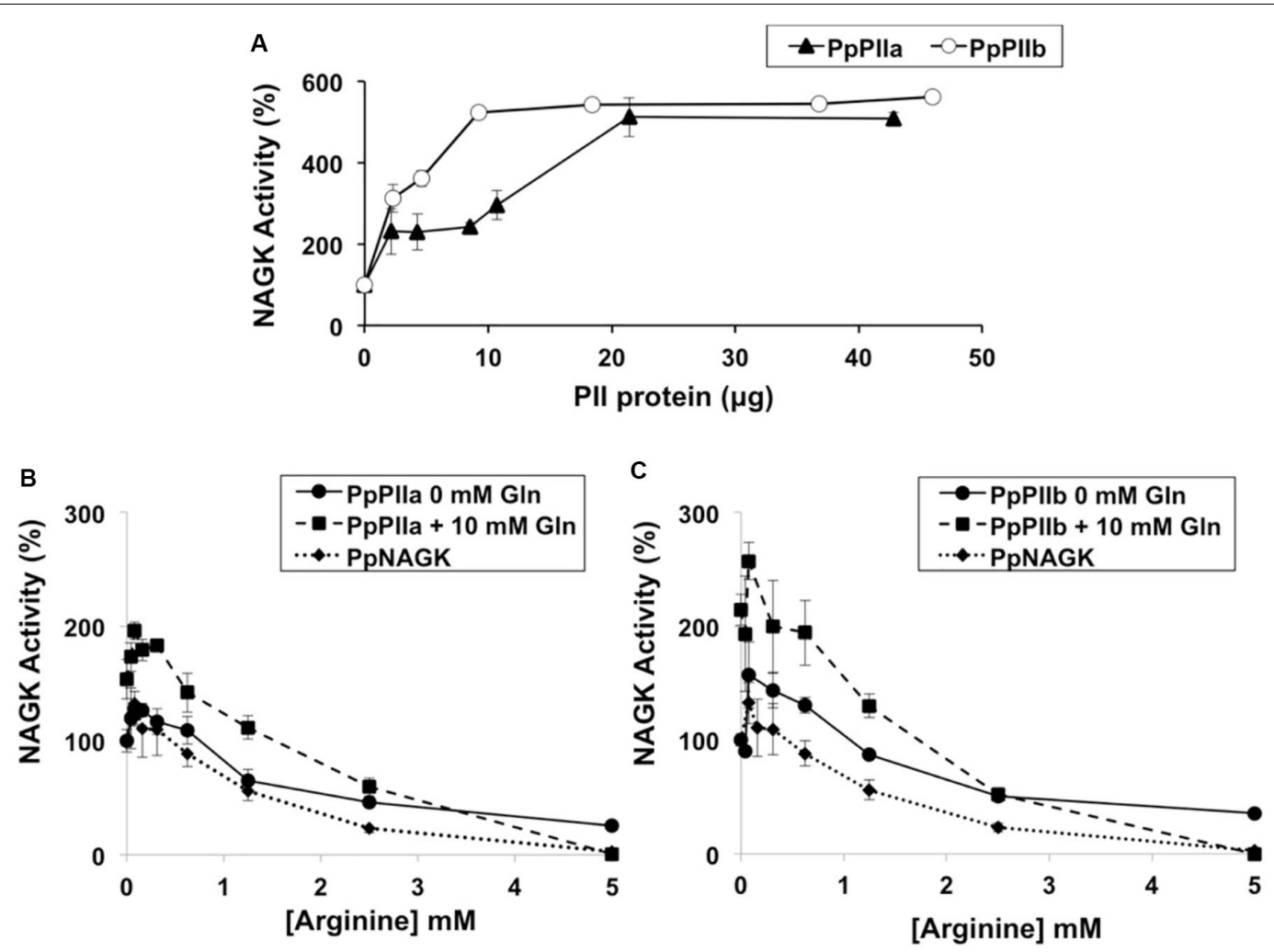

FIGURE 5 | Effects of PpPlla and PpPIlb on the PpNAGK activity. (A) Effect of increasing amount of PpPlla (black triangles) and PpPIlb (open circles) proteins on PpNAGK activity. The indicated amounts of PpPIl were mixed with $0.65 \mu \mathrm{g}$ PpNAGK, and the mixtures were placed at $4^{\circ} \mathrm{C}$ for 10 min to allow complex formation. The reaction was initiated by the addition of the reaction mixture into the PpNAGK-PpPII complex mixture. The $N$-acetylglutamylhydroxamate assay was used. (B) PpNAGK-PpPlla complex activity inhibition by arginine with or without added glutamine. (C) PpNAGK-PpPIlb complex activity inhibition by arginine with or without added glutamine. Glutamine $10 \mathrm{mM}$ (black squares); glutamine $0 \mathrm{mM}$ (black circles). PpNAGK activity inhibition by arginine is also shown (black triangles). To test the effect of arginine on the PpNAGK-PpPII complexes, PpPII was first added into the diluted PpNAGK solution, and the two proteins were placed at $4^{\circ} \mathrm{C}$ for $10 \mathrm{~min}$ to allow complex formation followed by the addition of arginine. The arginine effect was also tested in combination with $10 \mathrm{mM}$ glutamine as described above. The continuous spectrophotometric assay was used. Values are the mean \pm SD of three independent determinations. NAGK activities (100\%) were (A) $108.80 \pm 14.35$, (B) $726.15 \pm 71.58$, and (C) $563.17 \pm 29.68$ nkatal/mg protein. The reaction mixtures contained (A) 0.65 , (B) 0.35 , and (C) $0.35 \mu \mathrm{g}$ of PpNAGK protein. The observed increase of PpNAGK activity with PpPlla and PpPllb was significant by $t$-test with a $P<0.1$ and enhanced in presence of glutamine with a $P<0.05$. Arginine inhibition was significantly relieved by adding glutamine $(P<0.01)$ in both PpNAGK-PpP\| complexes. Each reaction mixture contained $0.35 \mu \mathrm{g}$ of PpNAGK protein and $0.7 \mu \mathrm{g}$ of PpPlla and $0.7 \mu \mathrm{g}$ PpPIlb.

PpPIIb enhanced PpNAGK activity already in the absence of glutamine. Nevertheless, under these experimental conditions, no significant differences in activity were observed at various 2-OG concentrations.

\section{Expression of PpPIla and PpPIlb Genes}

To further explore the potential roles of PII isoproteins in maritime pine, gene expression levels were analyzed during the last stages of embryogenesis and seed germination (Figure 6). The relative levels of PpPIIa transcripts were much higher than those $P p P I I b$ observed in all stages examined, with an upper abundance in the seed embryos.

\section{DISCUSSION}

A bioinformatics survey of the maritime pine transcriptome revealed the occurrence of two transcripts (PpPIIa and PpPIIb) encoding PII proteins (Supplementary Figure S1). They have similar molecular size but differ in their amino acid sequence (Figure 1). This finding is novel because only one form of PII has been reported to exist in other plant species (Chen et al., 2006). Interestingly, two PII homologs have also been identified in several pine species for which large transcriptomics data are available. In contrast, only one PII gene product has been found in spruce species (Figure 1). Taken together, our results suggest that the existence of PII variants is not a general characteristic of conifers and seems to be restricted to pines.

As the sequence of the maritime pine genome is still not available, we searched for PII homologs in the loblolly pine (P. taeda) genome (Neale et al., 2014). The goal was to figure out whether the two PII transcripts were encoded by distinct genes or they were the result of a differential splicing. The sequences for PtPIIa and PtPIIb were located in the same scaffold, but were interrupted by large gaps that prevented the retrieval of a complete gene structure. 


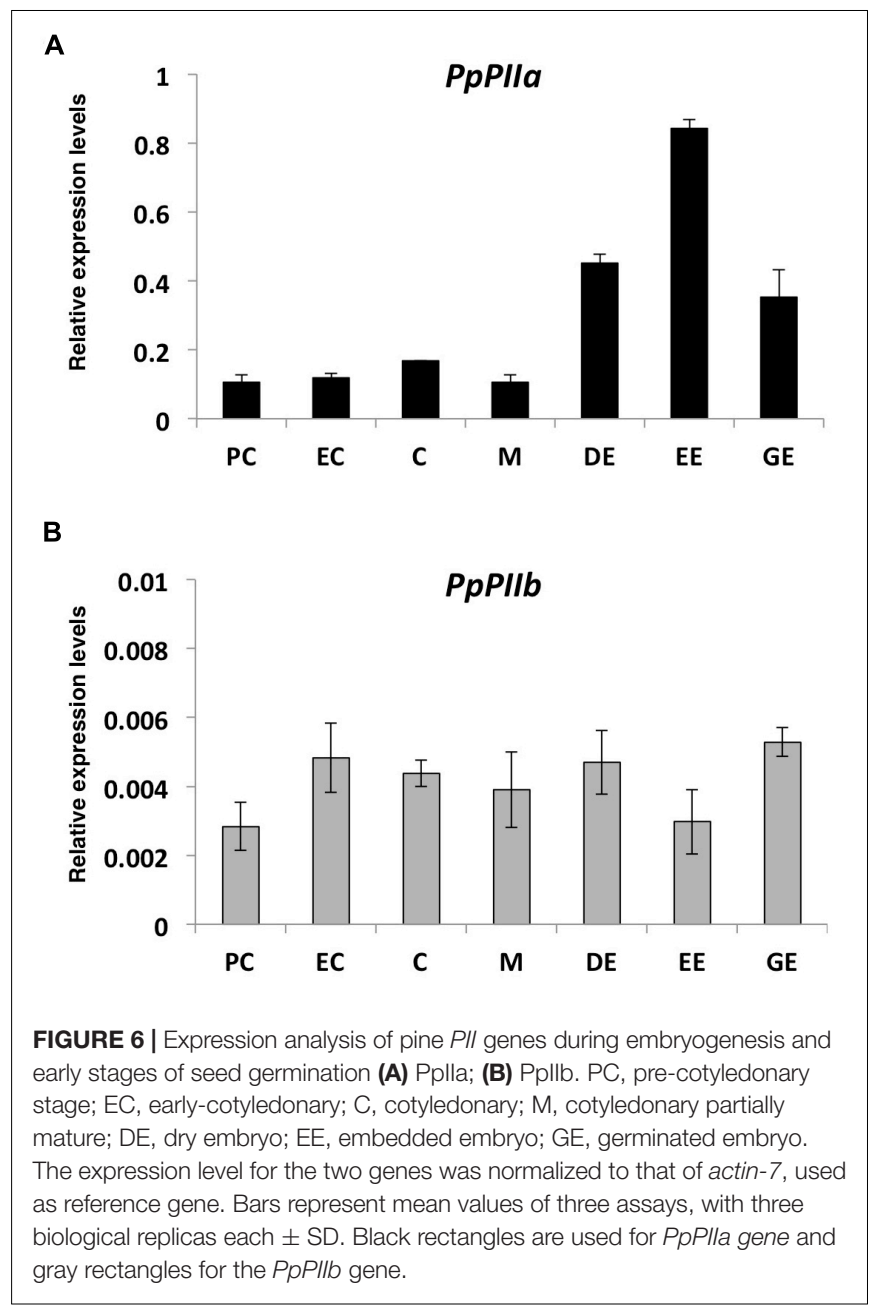

Considering the primary structure of their cDNAs, the most plausible explanation is that PtPIIa and PtPIIb are the result of alternative splicing of a single gene. No different 3'untranslated regions were amplified from a range of different pine tissues by rapid amplification of cDNA ends (RACE). The above conclusion is reinforced by the identification of a similar pattern of hybridizing bands in a Southern blot of pine genomic DNA digested with several restriction enzymes (Supplementary Figure S5).

Sequence analysis of the polypeptides encoded by PtPIIa and PtPIIb identified a putative CTP in their N-terminal end. Nevertheless, the existence of two forms of PII could be related with a distinct subcellular localization in pine cells. To investigate this hypothesis, we conducted subcellular localization studies (Figure 2). Our results confirmed that PpPIIa and PpPIIb are located in the chloroplastic stroma, as previously reported for their Arabidopsis PII homolog (Chen et al., 2006). PpPIIa and $\mathrm{PpPIIb}$ are therefore able to interact in vivo with their target enzyme, PpNAGK, which is located in the same compartment in pine cells (Llebrés et al., 2018b).

The three-dimensional models of PpPIIa and PpPIIb are highly similar to the previously described crystal structures of
PII proteins from Synechococcus and Arabidopsis (Mizuno et al., 2007; Llacer et al., 2008).

These two structurally characterized PII proteins lack a glutamine site, unlike PpPII proteins, judged from sequence comparisons and from the observation of activation of NAGK activity by glutamine addition to mixtures of PpNAGK and PpPII proteins (Figures 5B,C).

The ability to sense glutamine levels, and therefore the cellular $\mathrm{N}$ status, relies on a C-terminal extension of the PII polypeptide that is unique of plant proteins (Chellamuthu et al., 2014). The $\mathrm{Q}$ loop is disordered in the absence of glutamine, but becomes ordered when the amino acid is present, which triggers in turn a specific interaction with the basal part of the $\mathrm{T}$ loop. The signal is then transmitted through a conformational change that favors the interaction of PII with NAGK (Chellamuthu et al., 2014; Forchhammer and Lüddecke, 2016). The change of glutamate (PpPIIa) for lysine (PpPIIb) at position 18 is spatially close to the $\mathrm{Q}$ loop and therefore likely to affect the above mechanism or its regulation. As shown in Figure 3, it causes a major effect on the electrostatic features of this region.

Overexpression of recombinant PpPIIa and PpPIIb in E. coli allowed us to confirm their trimeric nature (Figure 4), in line with previous observations for PII proteins from plants and microorganisms (Chen et al., 2006; Forchhammer and Lüddecke, 2016). Moreover, the overproduction in E. coli of PpNAGK, the target enzyme of PpPII, enabled us to study the formation of PpNAGK-PpPIIa and PpNAGK-PpPIIb complexes. The binding of both PpPIIa and PpPIIb to PpNAGK increased the activity of this enzyme (Figure 5). A similar observation was previously reported in Arabidopsis (Chen et al., 2006). PpNAGK activation suggests high affinity of PpPIIa and PpPIIb for PpNAGK in the formation of regulatory complexes, what was experimentally confirmed by YTH analysis. The sequence changes between these two proteins at positions 18 (Glu18Lys) and near the T-loop (three amino acid changes) did not affect the formation of the complex with PpNAGK, as shown by sitedirected mutagenesis experiments with PpPIIa (Supplementary Figure S3). Together, the above results suggest that the observed differences between PpPIIa and PpPIIb regarding complex formation with PpNAGK are not only based in single amino acid changes.

To better characterize PpPII proteins, we also analyzed the effects of 2-OG, arginine, and glutamine on the formation of regulatory complexes with PpNAGK. The addition of increasing amounts of 2-OG did not affect PpNAGK activity when the enzyme from maritime pine was incubated in the absence of PpPIIa or PpPIIb (Supplementary Figure S4). Likewise, 2-OG did not influence PpNAGK activity when complexed with any of the two PpPII proteins, suggesting that, as in other plants having glutamine-sensing PII proteins (Chellamuthu et al., 2014), $2 \mathrm{OG}$ did not dissociate the complex of the two proteins. Actually, glutamine proved essential for PII-NAGK complex formation in Chlamydomonas and some plant species studied (excepting A. thaliana, which does not sense glutamine) but this appears not to be the case in maritime pine for any of it two PII proteins, although it might increase the affinity of these PpPII proteins for PpNAGK, a situation that is reminescent of that recently 
uncovered for the non-photoxynthetic alga Polytomella parva (Selim et al., 2020b).

It is well documented that the more sensitive assay for the PII-NAGK interaction is the relief of the inhibition of enzyme activity caused by arginine (Llacer et al., 2008). Chellamuthu et al. (2014) reported that glutamine is able to further relieve this feedback inhibition when NAGK is bound to PII. We have observed enhanced PpNAGK in vitro activity in the presence of PpPIIa and PpPIIb, when glutamine was present (Figure 5). The results suggest that PpPIIa and PpPIIb are equally effective in sensing glutamine and thus PII redundancy in pine does not appear to affect the sensing of glutamine. Alternatively, one may speculate that the occurrence of two PII variants might increase the dosage for sensing this amino acid, similarly as reported for enhanced glutamine biosynthesis in Populus (Castro-Rodríguez et al., 2015). Nevertheless, a differential role of PpPIIa and PpPIIb in other physiological conditions cannot be excluded.

In this regard, the expression patterns of both $P p P I I$ genes were analyzed at early stages of development to identify if each one may fulfill distinct roles during maritime pine embryogenesis and early growth (Figure 6). PpPIIa exhibited higher expression levels than $P p P I I b$ suggesting its predominance, at least at these stages of development. PpPIIa transcripts were particularly abundant at the end of maturation and the beginning of germination when arginine metabolism is highly active. In contrast, $P$ PPIIb displayed low expression levels at all stages examined (Figure 6). These results suggest different roles for these isoproteins, likely regulating in a different manner arginine metabolism through their interaction with PpNAGK.

\section{CONCLUSION}

In summary, we have identified two different forms of PII in maritime pine. They are most likely the splicing products of a single gene and their existence seems to be restricted to pines: a single PII has been identified in other conifer species and in angiosperms. PpPIIa and PpPIIb are trimeric proteins with similar three-dimensional structure and subcellular location. The PII-target enzyme PpNAGK is localized to the same compartment. The interactions of both recombinant PpPII variants and PpNAGK appear to be enhanced by glutamine, relieving the feedback inhibition of PpNAGK activity by arginine in the $\mathrm{mM}$ range. PpIIa appears to play a predominant role during maritime pine embryogenesis and germination.

\section{DATA AVAILABILITY STATEMENT}

All datasets generated for this study are included in the article/Supplementary Material.

\section{AUTHOR CONTRIBUTIONS}

ML, CV, FT, JV-M, and MP performed the experimental work. ML prepared the figures. LG was in charge of protein modeling.
FC and CA conceived the project, supervised the work, and wrote the manuscript with contributions from FT, MP, and LG.

\section{FUNDING}

This research work was supported by grants from "Ministerio de Ciencia e Innovación” (BIO2015-69285-R and RTI2018-094041B-I00) and Junta de Andalucía (BIO-474 and BIO-114).

\section{ACKNOWLEDGMENTS}

We are indebted to Dr. Rafael Cañas for adapting the coupled enzymatic assay to multi-well microtiter plates. We also thank Remedios Crespillo at the Molecular Biology laboratory (Universidad de Málaga Research Facilites) for excellent technical support.

\section{SUPPLEMENTARY MATERIAL}

The Supplementary Material for this article can be found online at: https://www.frontiersin.org/articles/10.3389/fpls.2020.00823/ full\#supplementary-material

FIGURE S1 | Primary structure of PpPII full-length cDNAs. Initial and stop codons are marked in red. The position of the primers utilized for the expression analysis is underlined in red.

FIGURE S2 | Purification of recombinant PpPlla and PpPllb proteins overproduced in E. coli. (A) Purification progress of PpPlla. (B) Purification progress of PpPllb. M, molecular makers; $\mathrm{C}$, bacterial crude extract; $\mathrm{F}$, flow-through eluate; W1, wash step 1; W2, wash step 2; lanes 1-5, elution of purified protein. Fractions 3 and 4 were collected for the studies performed in this work.

FIGURE S3 | Yeast two-hybrid interaction analysis. (A) Auxotrophic analysis of interaction of PpNAGK and PpPlla or PpPllb. Tranformants were analyzed in SD agar plates without tryptophan, leucine, and uracil, and several dilutions were made. (B) Diagram of amino acid changes performed in the isoprotein PpPlla (PpPllaMut1: Glu18Lys and PpPllaMut2: Val58Ala/Ala60Gly/Gly61Ala). (C) $\beta$-Galactosidase activity. Bars represent mean values of three assays, with three biological replicates each \pm SD; asterisk indicates significant difference between samples at $P<0.05$.

FIGURE S4 | Effect of 2-OG concentration on PpNAGK activity. The activity of enzyme was measured in the presence of varying amounts of 2-OG, either without PpPII protein added (black triangles), or in the presence of PpPlla (black squares) or PpPIllb (open circles) at the PpNAGK-PpPII ratios indicated. Each reaction mixture contained $0.65 \mu \mathrm{g}$ of PpNAGK protein and $6.5 \mu \mathrm{g}$ of PpPlla and $6.5 \mu \mathrm{g}$ PpPIllb. The $N$-acetylglutamylhydroxamate assay was used. Bars represent mean values of three independent experiments \pm SD.

FIGURE S5 | Southern blot analysis of pine genomic DNA. Isolated genomic DNA was digested with the restriction enzymes EcoRI, Hindlll y BamH, and hybridized with a PpPlla cDNA probe.

TABLE S1 | List of the gene specific primer sequences used in this work.

TABLE S2 | Characteristics of PpPlla and PpPllb polypeptides and processed proteins. CTP: chloroplast transit peptide. Sequences of PpPlla and PpPIllb were available at SustainPineDB v.3.0 (http://www.scbi.uma.es/sustainpinedb/ sessions/new). 


\section{REFERENCES}

Arcondeguy, T., Jack, R., and Merrick, M. (2001). PII signal transduction proteins, pivotal players in microbial nitrogen control. Microbiol. Mol. Biol. Rev. 65, 80-105. doi: 10.1128/mmbr.65.1.80-105.2001

Biasini, M., Bienert, S., Waterhouse, A., Arnold, K., Studer, G., Schmidt, T., et al. (2014). SWISS-MODEL: modelling protein tertiary and quaternary structure using evolutionary information. Nucleic Acids Res. 42, W252-W258.

Bradford, M. M. (1976). A rapid and sensitive method for the quantitation of microgram quantities of protein utilizing the principle of protein-dye binding. Anal. Biochem. 72, 248-254. doi: 10.1016/0003-2697(76)90527-3

Canales, J., Avila, C., Cantón, F. R., Pacheco-Villalobos, D., and Díaz-Moreno, S. (2012). Gene expression profiling in the stem of young maritime pine tres: detection of ammonium stress-responsive genes in the apex. Trees Struct. Funct. 26, 609-619. doi: 10.1007/s00468-011-0625-z

Canales, J., Bautista, R., Label, P., Noe, F. P., Pedro, S., Celia, M., et al. (2014). De novo assembly of maritime pine transcriptome: implications for forest breeding and biotechnology. Plant Biotechnol. J. 12, 286-299.

Cañas, R. A., Li, Z., Pascual, M. B., Castro-Rodríguez, V., Ávila, C., Sterck, L., et al. (2017). The gene expression landscape of pine seedling tissue. Plant J. 91, 1064-1087. doi: 10.1111/tpj.13617

Cañas, R. A., Pascual, M. B., de la Torre, F. N., Avila, C., and Cánovas, F. M. (2019). Resources for conifer functional genomics at the omics era. Adv. Bot. Res. 89, 39-76. doi: 10.1016/bs.abr.2018.11.002

Cánovas, F. M., Avila, C., Cantón, F. R., Cañas, R. A., and de la Torre, F. (2007). Ammonium assimilation and amino acid metabolism in conifers. J. Exp. Bot. 58, 2307-2318. doi: 10.1093/jxb/erm051

Cánovas, F. M., Cañas, R. A., de la Torre, F. N., Pascual, M. B., Castro-Rodríguez, V., and Avila, C. (2018). Nitrogen metabolism and biomass production in forest trees. Front. Plant Sci. 9:1449. doi: 10.3389/fpls.2018.01449

Cánovas, F. M., Cantón, F. R., Gallardo, F., García-Gutiérrez, A., and de Vicente, A. (1991). Accumulation of glutamine synthetase during early development of maritime pine seedlings (Pinus pinaster). Planta 185, 372-378. doi: 10.1007/ bf00201059

Cánovas, F. M., Valpuesta, V., and Núñez de Castro, I. (1984). Characterization of tomato leaf glutamine synthetase. Plant Sci. Lett. 37, 79-85. doi: 10.1016/03044211(84)90207-4

Cantón, F. R., García-Gutiérrez, A., Crespillo, R., and Cánovas, F. M. (1996). High-level expression of Pinus sylvestris glutamine synthetase in Escherichia coli. Production of polyclonal antibodies against the recombinant protein and expression studies in pine seedlings. FEBS Lett. 393, 205-210. doi: 10.1016/ 0014-5793(96)00886-1

Castro-Rodríguez, V., García-Gutiérrez, A., Cañas, R. A., Pascual, B., Avila, C., and Cánovas, F. M. (2015). Redundancy and metabolic regulation of the glutamine synthetase gene family in poplar. BMC Plant Biol. 15:20. doi: 10.1186/s12870014-0365-5

Chellamuthu, V. R., Ermilova, E., Lapina, T., Luddecke, J., Minaeva, E., Herrmann, C., et al. (2014). A widespread glutamine sensing mechanism in the plant kingdom. Cell 159, 1188-1199. doi: 10.1016/j.cell.2014.10.015

Chen, Y. M., Ferrar, T. S., Lohmeier-Vogel, E. M., Morrice, N., Mizuno, Y., Berenger, B., et al. (2006). The PII signal transduction protein of Arabidopsis thaliana forms an arginine regulated complex with plastid $\mathrm{N}$-acetyl glutamate kinase. J. Biol. Chem. 281, 5726-5733. doi: 10.1074/jbc.m510945200

Coruzzi, G. M., and Zhou, L. (2001). Carbon and nitrogen sensing and signaling in plants: emerging 'matrix effects. Curr. Opin. Plant Biol. 4, 247-253. doi: 10.1016/s1369-5266(00)00168-0

D’Apuzzo, E., Valkov, V. T., Parlati, A., Omrane, S., Barbulova, A., Sainz, M. W., et al. (2015). PII overexpression in Lotus japonicus affects nodule activity in permissive low nitrogen conditions and increases nodule numbers in high nitrogen treated plants. Mol. Plant Microbe Interact. 28, 432-442. doi: 10.1094/ mpmi-09-14-0285-r

El-Azaz, J., de la Torre, F., Avila, C., and Cánovas, F. M. (2016). Identification of a small protein domain present in all plant lineages that confers high prephenate dehydratase activity. Plant J. 87, 215-229. doi: 10.1111/tpj. 13195

Ferrario-Méry, S., Besin, E., Pichon, O., Meyer, C., and Hodges, M. (2006). The regulatory PII protein controls arginine biosynthesis in
Arabidopsis. FEBS Lett. 580, 2015-2020. doi: 10.1016/j.febslet.2006 02.075

Ferrario-Méry, S., Meyer, C., and Hodges, M. (2008). Chloroplast nitrite uptake is enhanced in Arabidopsis PII mutants. FEBS Lett. 582, 1061-1066. doi: 10.1016/ j.febslet.2008.02.056

Forchhammer, K., and Lüddecke, J. (2016). Sensory properties of the PII signalling protein family. FEBS J. 283, 425-437. doi: 10.1111/febs.13584

Gent, L., and Forde, B. (2017). How do plants sense their nitrogen status? J. Exp. Bot. 68, 2531-2539. doi: 10.1093/jxb/erx013

Gómez-Maldonado, J., Cánovas, F. M., and Avila, C. (2004). Molecular analysis of the 5-upstream region of a gibberellin-inducible cytosolic glutamine synthetase gene (GS1b) expressed in pine vascular tissue. Planta 218, 1036-1045. doi: 10.1007/s00425-003-1185-2

Heinrich, A., Maheswaran, M., Ruppert, U., and Forchhammer, K. (2004). The Synechococcus elongatus PII signal transduction protein controls arginine synthesis by complex formation with $\mathrm{N}$-acetyl-l-glutamate kinase. Mol. Microbiol. 52, 1303-1314. doi: 10.1111/j.1365-2958.2004.04058.x

Jiang, P., Pelinska, J. A., and Ninfa, A. J. (1998). Reconstitution of the signaltransduction bicyclic cascade responsible for the regulation of Ntr gene transcription in Escherichia coli. Biochemistry 37, 12795-12801. doi: 10.1021/ bi9802420

Kumar, S., Stecher, G., and Tamura, K. (2016). MEGA 7: molecular evolutionary genetic analysis version 7.0 for bigger datasets. Mol. Biol. Evol. 33, 1870-1874. doi: $10.1093 / \mathrm{molbev} / \mathrm{msw} 054$

Li, G., and Coleman, G. D. (2019). Nitrogen storage and cycling in trees. Adv. Bot. Res. 89, 127-148.

Liu, Y., Schiff, M., and Dinesh-Kumar, S. P. (2002). Virus-induced gene silencing in tomato. Plant J. 31, 777-786. doi: 10.1046/j.1365-313x.2002.01394.x

Llácer, J. L., Contreras, A., Forchhammer, K., Marco-Marín, C., Gil-Ortiz, F., Maldonado, R., et al. (2007). The crystal structure of the complex of PII and acetylglutamate kinase revelas how PII controls the storage of nitrogen as arginine. Proc. Natl. Acad. Sci. U.S.A. 104, 17644-17649. doi: 10.1073/pnas. 0705987104

Llacer, J. L., Fita, I., and Rubio, V. (2008). Arginine and nitrogen storage. Curr. Opin. Struct. Biol. 18, 673-681. doi: 10.1016/j.sbi.2008.11.002

Llebrés, M. T., Avila, C., Cánovas, F. M., and Klimaszewska, K. (2018a) Root growth of hybrid Pinus strobus (L.) and P. wallichiana (A. B. Jacks.) somatic plants is affected by the nitrogen composition of the somatic embryo germination medium. Trees Struct. Funct. 32, 371-381. doi: 10.1007/s00468017-1635-2

Llebrés, M. T., Pascual, M. B., Debille, S., Trontin, J. F., Avila, C., and Cánovas, F. M. (2018b). The role of arginine metabolic pathway during embryogenesis and germination in maritime pine (Pinus pinaster Ait.). Tree Physiol. 38, 471-484. doi: 10.1093/treephys/tpx133

Mizuno, Y., Moorhead, G. B., and Ng, K. K. (2007). Structural basis for the regulation of $\mathrm{N}$-acetylglutamate kinase by PII in Arabidopsis thaliana. J. Biol. Chem. 282, 35733-35740. doi: 10.1074/jbc.m707127200

Muro-Pastor, M. I., Reyes, J. C., and Florencio, F. J. (2005). Ammonium assimilation in cyanobacteria. Photosynth. Res. 83, 135-150. doi: 10.1007/ s11120-004-2082-7

Neale, D. B., Wegrzyn, J. L., Stevens, K. A., Jill, L. W., John, D. L., Brian, Y. L., et al. (2014). Decoding the massive genome of loblolly pine using haploid DNA and novel assembly strategies. Genome Biol. 15:R59. doi: 10.1186/gb-2014-15-3-r59

Ninfa, A. J., and Atkinson, M. R. (2000). PII signal transduction proteins. Trends Microbiol. 8, 172-179. doi: 10.1016/s0966-842x(00)01709-1

Parlatti, A., Valkov, V. T., D’Apuzzo, E., Alves, L. M., Petrozza, A., Summerer, S., et al. (2017). Ectopic expression of PII induces stomatal closure in Lotus japonicus. Front. Plant Sci. 8:1299. doi: 10.3389/fpls.2017.01299

Pettersen, E. F., Goddard, T. D., Huang, C. C., Couch, G. S., Greenblatt, D. M., Meng, E. C., et al. (2004). UCSF chimera-a visualization system for exploratory research and analysis. J. Comput. Chem. 25, 1605-1612. doi: 10.1002/jcc.20084

Ritz, C., and Spiess, A-N. (2008). qpcR: an R package for sigmoidal model selection in quantitative real-time polymerase chain reaction analysis. Bioinformatics. 24 , 1549-1551. doi: 10.1093/bioinformatics/btn227

Robles-Rengel, R., Florencio, F. J., and Muro-Pastor, M. I. (2019). Redox interference in nitrogen status via oxidative stress is mediated by 2-oxoglutarate in cyanobacteria. New Phytol. 224, 216-228. doi: 10.1111/nph.15979 
Selim, K. A., Ermilova, E., and Forchhammer, K. (2020a). From cyanobacteria to Archaeplastida: new evolutionary insights into PII signalling in the plant kingdom. New Phytol. doi: 10.1111/nph.16492. [Epub ahead of print].

Selim, K. A., Lapina, T., Forchhammer, K., and Ermilova, E. (2020b). Interaction of N-acetyl-l-glutamate kinase with the PII signal transducer in the nonphotosynthetic alga Polytomella parva: Co-evolution towards a heterooligomeric enzyme. FEBS J. 287, 465-482. doi: 10.1111/febs.14989

Todd, C. D., Cooke, J. E., Mullen, R. T., and Gifford, D. J. (2001). Regulation of loblolly pine (Pinus taeda L.) arginase in developing seedling tissue during germination and post-germinative growth. Plant Mol. Biol. 45, 555-565.

Todd, C. D., and Gifford, D. J. (2003). Loblolly pine arginase responds to arginine in vitro. Planta 217, 610-615. doi: 10.1007/s00425-003-1022-7

Trontin, J. F., Teyssier, C., Morel, A., Harvengt, J., and Lelu-Walter, M. A. (2016). "Prospects for new variety deployment through somatic embryogenesis in maritime pine," in Vegetative Propagation of Forest Trees, eds Y.-S. Park, J. M. Bonga, and H.-K. Moon (Seoul: Korea Forest Research Institute), 572-606.
Urigh, R. G., Ng, K. K. S., and Moorhead, G. B. G. (2009). PII in higher plants: a modern role for an ancient protein. Trends Plant Sci. 14, 505-511. doi: 10.1016/j.tplants.2009.07.003

Yang, J., Yan, R., Roy, A., Xu, D., Poisson, J., and Zhang, Y. (2015). The I-TASSER suite: protein structure and function prediction. Nat. Methods 12, 7-8. doi: 10.1038/nmeth.3213

Conflict of Interest: The authors declare that the research was conducted in the absence of any commercial or financial relationships that could be construed as a potential conflict of interest.

Copyright (c) 2020 Llebrés, Pascual, Valle, de la Torre, Valderrama-Martin, Gómez, Avila and Cánovas. This is an open-access article distributed under the terms of the Creative Commons Attribution License (CC BY). The use, distribution or reproduction in other forums is permitted, provided the original author(s) and the copyright owner(s) are credited and that the original publication in this journal is cited, in accordance with accepted academic practice. No use, distribution or reproduction is permitted which does not comply with these terms. 